\title{
Communication
}

\section{In Situ Assembly of Gold Nanoparticles in the Presence of Poly-DADMAC Resulting in Hierarchical and Highly Fractal Nanostructures}

\author{
J. Michael Köhler*(1) and Jonas Kluitmann (1)
}

check for updates

Citation: Köhler, J.M.; Kluitmann, J. In Situ Assembly of Gold Nanoparticles in the Presence of Poly-DADMAC Resulting in Hierarchical and Highly Fractal Nanostructures. Appl. Sci. 2021, 11, 1191. https://doi.org/

10.3390/app11031191

Academic Editor: Andrea Atrei

Received: 10 December 2020

Accepted: 23 January 2021

Published: 28 January 2021

Publisher's Note: MDPI stays neutral with regard to jurisdictional claims in published maps and institutional affiliations.

Copyright: (c) 2021 by the authors. Licensee MDPI, Basel, Switzerland. This article is an open access article distributed under the terms and conditions of the Creative Commons Attribution (CC BY) license (https:// creativecommons.org/licenses/by/ $4.0 /)$.
Group for Physical Chemistry/Microreaction Technology, Institute for Chemistry and Biotechnology, Technische Universität Ilmenau, 98694 Ilmenau, Germany; Jonas.kluitmann@tu-ilmenau.de

* Correspondence: michael.koehler@tu-ilmenau.de; Tel.: +49-3677-693-629

Featured Application: The investigated composed particles are of interest for future applications for nanoparticle-based surface-enhanced Raman scattering (SERS) analytics and as components in plasmonic sensing, such as biomolecules.

Abstract: The presence of the polycationic macromolecule poly(diallyldimethylammonium chloride) (poly-DADMAC) has a strong effect on the shape and size of colloidal gold nanoparticles formed by the reduction of tetrachloroauric acid with ascorbic acid in aqueous solution. It slows down nanoparticle growth and supports the formation of nonspherical, partially highly fractal and hierarchical nanoparticle shapes. Four structural levels have been recognized from the near-spherical gold nanoparticles in the lower nanometer range over compact aggregates in the midnanometer range and flower and star-like particles in the submicron range up to larger filamentous aggregates. High-contrast scanning electron microscope (SEM) images show that single gold nanoparticles and clusters of them are connected by bundles of macromolecules in large aggregates. The investigation showed that a large spectrum of different nanoparticle shapes and sizes can be accessed by tuning the poly-DADMAC concentrations and their ratio to other reactants. The nanoassemblies with a very high specific surface area might be of interest for SERS and heterogeneous catalysis.

Keywords: nanoparticles; hierarchical structures; particle aggregation; fractal nanoparticles; electrostatic interaction

\section{Introduction}

The investigation of gold nanoparticles is motivated by their electronic properties [1,2]. They are used for bioanalytical applications such as pregnancy tests and immunoassays for virus proteins [3-6]. The electromagnetic resonance of these so-called "plasmonic" particles is strongly influenced by their shape, size and morphology. Instead of the typical absorption maximum around $530 \mathrm{~nm}$, longer wavelength absorption peaks arise in the case of nonspherical gold nanoparticles such as nanorods [7,8]. By increasing the aspect ratio, the resonance can be tuned into the near-infrared region [9].

A bathochromic shift of absorption is also observed in the case of particle-particle interactions. The effect of these interactions is exploited in a variety of analytical applications. [10,11]. The color change due to aggregation of the negatively charged gold nanoparticles can be used for the sensitive detection of low concentrations of polycationic molecules. An aggregation of negatively charged gold nanoparticles can be used for the sensitive detection of low concentrations of polycationic molecules. Such negatively charged gold nanoparticles are obtained, normally, from wet chemical synthesis by the reduction of tetrachloroauric acid with an excess of citric or ascorbic acid, for example. The measurement of low concentrations of poly(diallyldimethylammonium) polycations in river water is another example for this analytical application [12,13]. Besides this analytical aspect, the interaction of forming metal nanoparticles with ionic surfactants and 
macromolecules is of interest for modulating the formation of nanoparticles and achieving different nanoparticle shapes. In addition, the interaction between the gold nanoparticles and oppositely charged macromolecules offers a strategy for altering the morphology of the gold nanoparticles and initiating nanoparticle assembling [14]. The nanoparticle assembling in general [15-17] and the interaction of metal nanoparticles with organic and biomacromolecules are of interest for the development of new nanomaterials and new complex architectures $[18,19]$ and for special applications in nanobiotechnology, biodiagnostics [20] and theranostics [21,22]. Besides the factors that determine the crystallographic structures and shape of the gold nanoparticles (polynuclear spheres, nanocubes, triangular or hexagonal nanoprisms and nanorods, for example), electrostatic interactions between the particles play a crucial role in the formation of structures and assemblies of different shapes and sizes [23-28]. These interactions account for the colloidal stability and the formation of nonspherical nanoparticles [29] such as star-like nanoaggregates [30]; networks formed by in situ interaction of the particles during the growth process [31]; and formation of ellipsoidal, dumbbell and astragal-like shapes of polymer-containing nanoparticles [32]. The synthesis of nanoparticle structures in the presence of macromolecules also depends on these electrostatic interactions. These electrostatic interactions can occur between nascent gold nanoparticles and the macromolecules during the formation and growth processes [33-35]. The binding between particles and macromolecules is supported by attractive Coulomb forces between negatively charged metal nanoparticles and positively charged macromolecules.

A regular connection between smaller and larger metal nanoparticles has been achieved by a protein-assisted assembly using bovine serum albumin (BSA) [36]. In this case, a homogeneous population of raspberry-like nanoclusters with a large core and a shell of satellite particles was prepared, whereby the electronic coupling between particles could be concluded from the detection of a bathochromic shift in the optical absorption spectrum. The bathochromic shift of plasmonic resonance is typical for clustered gold nanoparticles, as found, for example, in former studies in the presence of polyvinylalcohol [37] and BSA [38]. Besides the adhesive effect of protein molecules, an electrostatic interaction between gold nanoparticles and molecules can take place during the formation and growth process in a wet chemical nanoparticle synthesis with synthetic macromolecules. The silver triangle formation by the addition of poly(sodium 4-styrenesulfonate) (PSS) [39] might be facilitated by electrostatic support of particle self-polarization by the polyanions [40]. A strong effect on the formation and assembly behavior of metal nanoparticles should also be expected in the presence of positively charged polyionic molecules. Besides the formation of regular assembly structures, it is of interest to investigate how larger aggregates between macromolecules and nanoparticles are formed and which structures can arise. Therefore, the formation of gold nanoparticles and nanoparticle assemblies in the presence of the polycationic macromolecule poly-DADMAC is investigated here.

\section{Materials and Methods}

Ascorbic acid (Alfa Aesar; 99+\%), poly(diallyldimethylammonium chloride) solution (ALDRICH, molecular weight $\leq 100 \mathrm{kDA}, 35 \mathrm{wt} . \%$ in water, PCode: 100103420), poly(sodium 4-styrenesulfonate) (ALDRICH, $1000 \mathrm{kDa}$, PCode: 1002572468) and tetrachloroauric acid trihydrate, $\mathrm{HAuCl}_{4}$ (ROTH, p.a.), were used as received without further purification. All solutions were set up with water from a reverse osmosis plant.

The particles were synthesized in agitated microreaction tubes by mixing appropriate amounts of $0.1 \mathrm{wt} . \%$ and $0.01 \mathrm{wt} . \%$ aqueous poly-DADMAC solutions, $1 \mathrm{mM} \mathrm{HAuCl}_{4}$ and water to a final reaction volume of $1 \mathrm{~mL}$ and initiating the reaction by adding $2 \mathrm{mM}$ ascorbic acid. Concentrations given with the samples are always final concentrations in the reaction dispersion. The synthesis experiments were carried out at room temperature $\left(20^{\circ} \mathrm{C}\right)$. For the formation of assembly particles, firstly, the polymer solution was diluted with water. The mixing ratio was chosen to achieve a final volume of $1 \mathrm{~mL}$ in each experiment. Secondly, the reducing agent (ascorbic acid) was added and mixed by vigorous vortexing 
for about $20 \mathrm{~s}$. In the last step, the metal precursor $\left(\mathrm{HAuCl}_{4}\right)$ was added in a concentration of $1 \mathrm{mM}$. The total ion concentration was in the submillimolar or micromolar range in the final reaction mixture, typically. No additional salt was added. The ionic strength was given by the ionic reactants PDADMAC and $\left[\mathrm{HAuCl}_{4}\right]$, which was in the range up to $400 \mathrm{ppm}$ (PDADMAC) and $0.2 \mathrm{mM}\left(\left[\mathrm{HAuCl}_{4}\right]\right)$. Additional chloride ions were generated by the reaction of tetrachloroaurate. Therefore, it was expected that the poly-DADMAC would be highly ionized under the applied experimental conditions.

The sedimentation of particles was comparatively slow. In a standard UV/VIS spectrometric cuvette $(1 \mathrm{~cm})$, beginning sedimentation was proved after about $5 \mathrm{~h}$ (Supplementary Figure S1). The particles were stable and could be redispersed by support of ultrasound.

Dynamic Light Scattering (DLS) measurements were conducted with a Zetasizer NanoZS (Malvern Panalytical). For the DLS measurements $\left(25^{\circ} \mathrm{C}\right.$, aqueous solution, absorbance: 0.3 , viscosity: $0.8872 \mathrm{cP}$, equilibration time: $120 \mathrm{~s}$, measurement angle: $173^{\circ}$, backscattering mode, three single measurements per sample, 70 size classes between 1 and $2500 \mathrm{~nm}$ ), $60 \mu \mathrm{L}$ of the as-obtained samples were transferred to a single-use cuvette and the cuvette capped off. The DLS measurements were performed 4 days after particle preparation and a redispersion ( 3 min shaking with ultrasound). In the DLS measurements, PDIs in the range between about 0.1 and 0.5 were found. Details are given in the supplementary table. SEM images were obtained in a Hitachi S-4800 FESEM (secondary electron signal, acceleration voltage: $25 \mathrm{kV}$ ) and optical spectra were measured in a SPECORD 200 (Analytik Jena). For the SEM measurements, the as-obtained samples were drop-casted onto silicon chips, dried in air and washed with deionized water.

From the point of view of characterization of nanoparticle assemblies, a combination of spectrophotometry, DLS measurements and contrast-enhanced SEM imaging (measurement by secondary electron detector) was chosen. These three methods address very different aspects of the formation of particle aggregates. Spectrophotometry supplies information about the electronic states, the so-called particle plasmonic resonances and their change due to electronic coupling in the case of particle contact. DLS measurements supply information about particle mobility (Brownian motion), which is related to the mass and shape of particles and the properties of the embedding medium (solution, swelling). Finally, the contrast-enhanced SEM measurements allow the combining of signals from optimal imaging of materials with a high yield of secondary electrons and low transparency (metals) with signals from optimal imaging of materials with a low yield of secondary electrons and high electron beam transparency.

\section{Results and Discussion}

The well-known reduction of tetrachloroauric acid with ascorbic acid in aqueous solution at room temperature leads to gold nanoparticles between about 10 and $20 \mathrm{~nm}$ [41,42]. The presence of the polycationic macromolecule poly-DADMAC leads to particles of different characters and aggregations. Typically, polynuclear compact elementary particles of about $10 \mathrm{~nm}$ diameter are observed, but the in situ assembly behavior is dependent on the poly-DADMAC concentration. Upon the reduction of $50 \mathrm{nmol} \mathrm{HAuCl}_{4}$ with $100 \mathrm{nmol}$ ascorbic acid in $1 \mathrm{~mL}$ aqueous solution (Figure 1), the aggregation tendency of the elementary particles is already visible at a poly-DADMAC concentration of $8 \mathrm{ppm}$, leading to compact aggregate particles of about $75 \mathrm{~nm}$. These particles sometimes aggregate further to form larger compact particle clusters (Figure 1h). Typically, a mixture of small particles (between about 6 and $30 \mathrm{~nm}$ ), medium-sized particles of about $80 \mathrm{~nm}$ and aggregates in the submicron range is formed (Figure 1g). In contrast, characteristic dendritic-shaped clusters of small gold nanoparticles are found at a poly-DADMAC concentration of $60 \mathrm{ppm}$. They are formed with a typical size of about $0.23 \mu \mathrm{m}$ and a comparatively high yield as confirmed by DLS measurements (Figure 1a) and by the SEM images (Figure 1b). A reduction of the particle size is observed and shorter dendritic branches are formed if the poly-DADMAC concentration is slightly lowered (Figure 1c,d). A further reduction of the polycation concentration results in aggregate particles with a size of about $80 \mathrm{~nm}$, which 
are obviously composed of elementary particles of about $10 \mathrm{~nm}$ in diameter (DLS spectrum and SEM image in Figure 1e,f). The DLS spectra show an increase in the mean particle size with the increase in poly-DADMAC concentration up to $400 \mathrm{ppm}$ (Figure 2). It has to be reconsidered that the DLS measurements supply only a rough estimation for the size of larger nonspherical aggregates consisting of particle clusters and macromolecular filaments. Zeta potentials in the positive range (about +30 to $+50 \mathrm{mV}$ ) have been observed in all cases of particle preparation in the presence of PDADMAC, as expected (Figure 2).
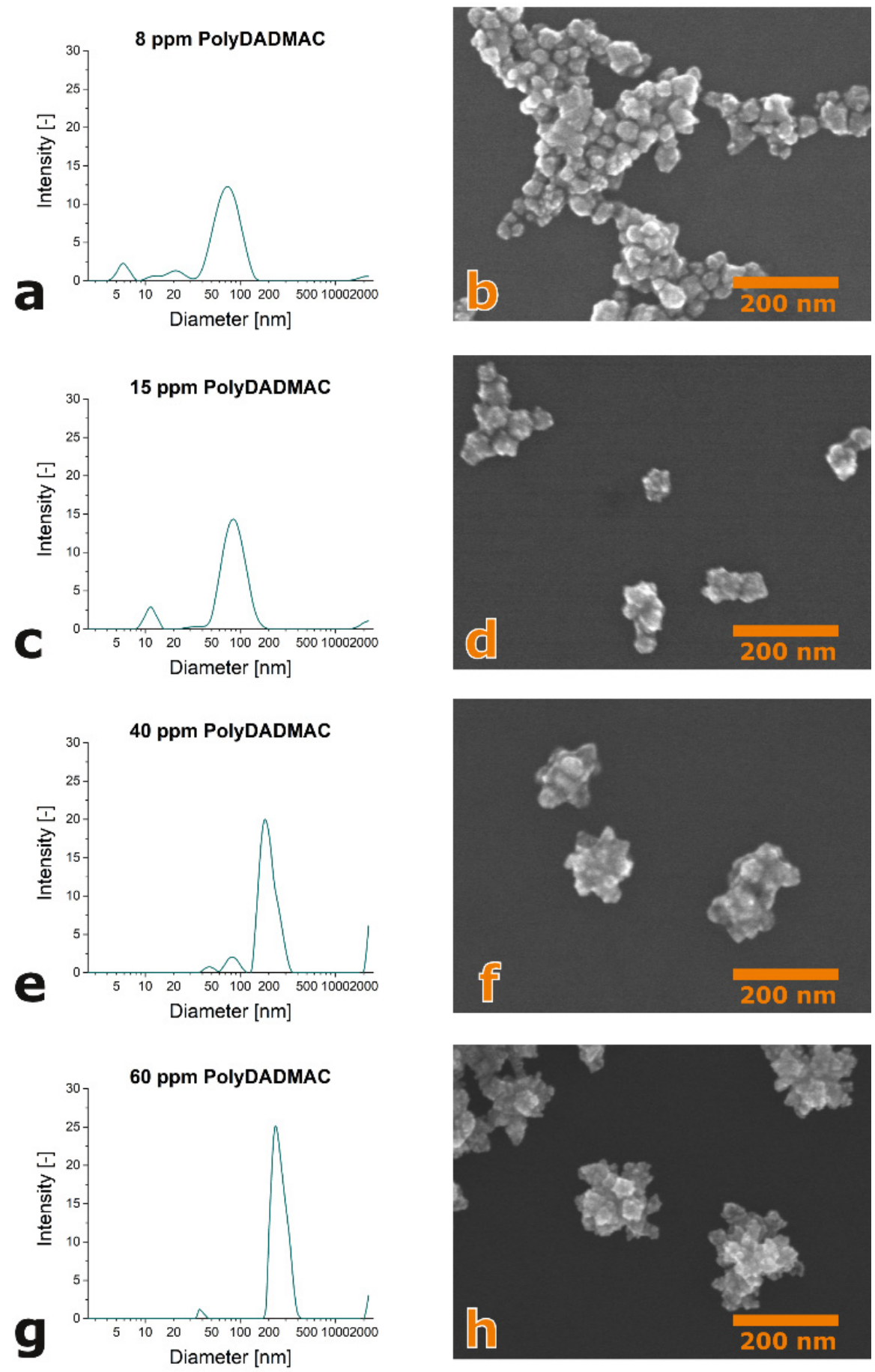

Figure 1. Dynamic Light Scattering (DLS) spectra and scanning electron microscope (SEM) images of gold nanoparticles formed in the presence of poly-DADMAC at $50 \mu \mathrm{M} \mathrm{HAuCl}_{4}$ and $100 \mu \mathrm{M}$ ascorbic acid in aqueous solution: (a,b) 8 ppm poly-DADMAC, (c,d) 15 ppm poly-DADMAC, (e,f) 30 ppm poly-DADMAC and (g,h) 60 ppm poly-DADMAC. 


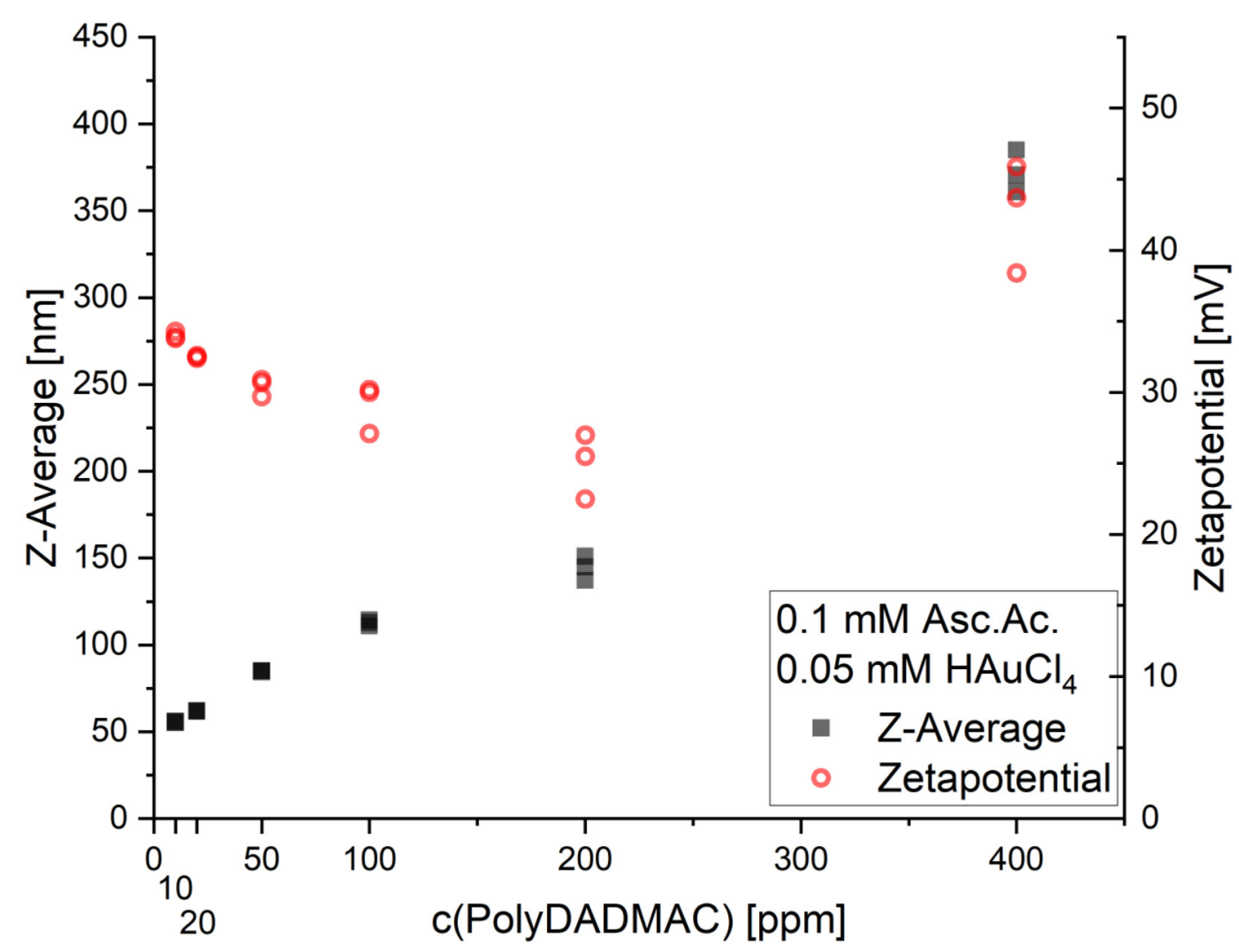

a

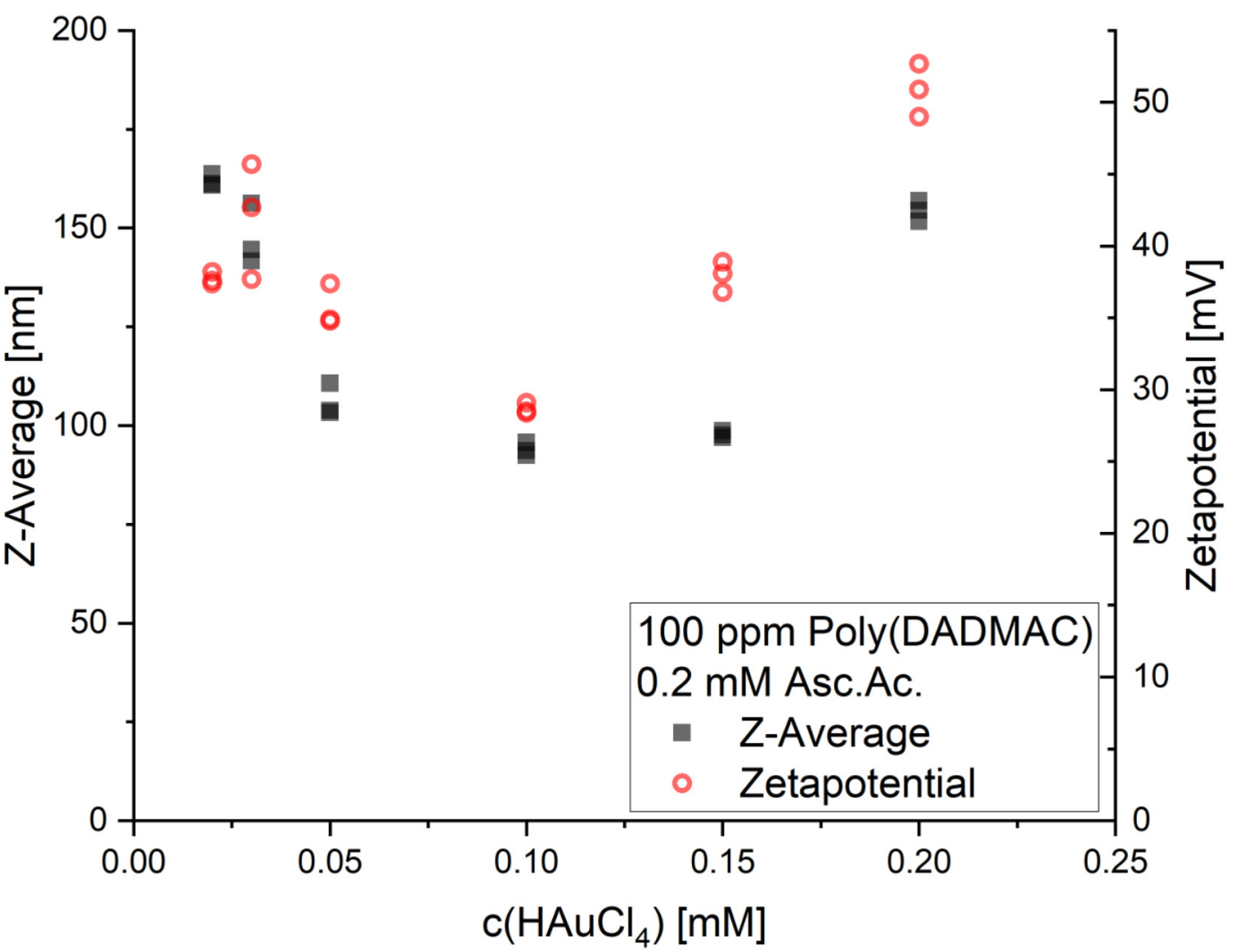

Figure 2. Dependence of the main particle fraction in the DLS spectra on reactant concentrations: (a) dependence on $\mathrm{HAuCl}_{4}$ concentration; (b) dependence on poly-DADMAC concentration.

Evidence of the differences in the aggregate shapes of the particles can be seen in the changes observed in the plasmon resonance spectra. The typical absorption peak of 
compact gold nanoparticles between 510 and $600 \mathrm{~nm}$ arises after the synthesis at lower poly-DADMAC concentrations. The peak wavelength is only moderately redshifted (to about $560 \mathrm{~nm}$ ) in comparison with the well-known resonance of small spherical gold nanoparticles at about $530 \mathrm{~nm}$ if poly-DADMAC is added at a low concentration (8 ppm). The increase in poly-DADMAC concentration causes a bathochromic shift of the peak maximum and a strong increase in the absorption in the near-infrared (NIR) range. The optical spectra show the appearance of a broad band above $800 \mathrm{~nm}$ with increasing polyDADMAC content. It is assumed that this increase is due to the electronic interaction of metallic nanoparticles coming in contact with each other by the aggregation process caused by the macromolecules (Figure 3). The strong increase in NIR absorption can be attributed to the formation of the dendritic structure of the formed particles. It corresponds to the long-wavelength absorption of nonspherical gold nanoparticles-nanorods, platelets or complex crystal structures-with higher aspect ratios [43-45].

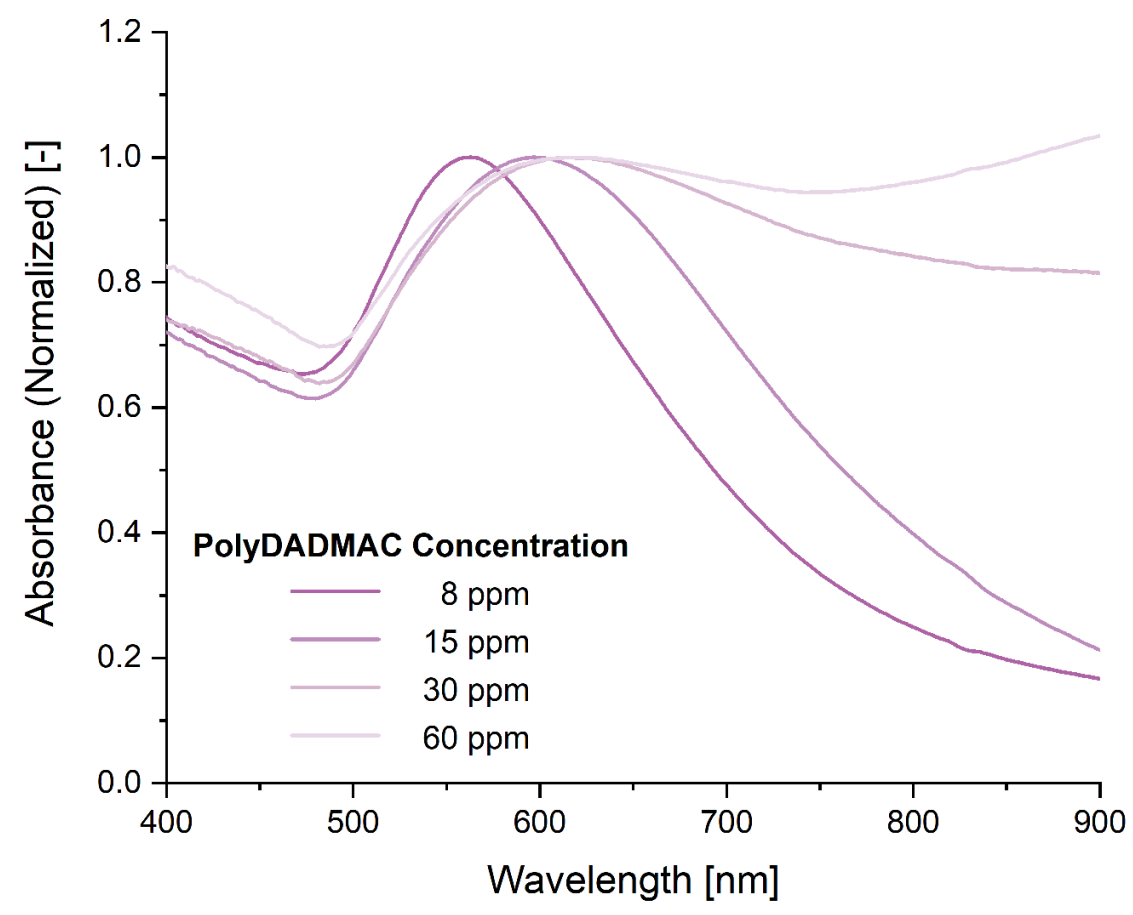

Figure 3. Bathochromic shift of absorption maximum and increase in near-infrared absorption with increasing poly-DADMAC concentration during the formation of gold nanoparticles by the reduction of $50 \mu \mathrm{M} \mathrm{HAuCl}_{4}$ with $100 \mu \mathrm{M}$ ascorbic acid.

Most DLS measurements indicate the formation of particles with an apparent diameter greater than two microns and indicate the formation of particles and clusters in the midnanometer and submicron range as well. The formation of larger aggregates was confirmed by SEM images (Figure 4) and by light microscopy. Typically, the aggregates show a filamentous morphology and consist of many single particles. The sizes of these filamentous aggregates are mainly between about two and six microns. The preferential appearance of clusters in this size range and the rough estimation of size ranges in solution by DLS measurements indicate that the clusters are already present in the solution and not formed during the drying process in the preparation of chips for SEM imaging. Contrast-enhanced SEM imaging of native deposited colloids on polished silicon chip surfaces-without any additional deposition of conductive material for SEM sample preparation-shows that larger aggregates of metal nanoparticles are formed in which the connections between metal particles are due to small molecular filaments. These connecting filaments become visible in image processing under strong contrast enhancement (Figure 5). The length of these filaments is in the order of magnitude of one or a few microns. Their diameter can be estimated to be below $20 \mathrm{~nm}$. The structure of the filaments and the low contrast in SEM 
imaging indicate the presence of macromolecules. In the absence of other reactants, the assumption is that the filaments are mainly formed by poly-DADMAC. The incorporation of gold nanoparticles inside the aggregates is plausible because they are negatively charged after their formation by the reduction of tetrachloroauric acid by ascorbic acid. Thus, the large aggregates are probably formed due to electrostatic binding between the negatively charged metal nanoparticles and the positively polycationic macromolecules. On the one hand, the poly-DADMAC molecules glue the nanoparticles to each other; on the other hand, the metal particles act as knots in the macromolecular network. There is likely a competition taking place between solvent and nanoparticle interactions with the ammonium groups. This effect, the mobility of polymer chains and repulsive forces between free ammonium groups lead to the formation of the observed noncompact aggregates in the lower micrometer range, as observed in the SEM images.

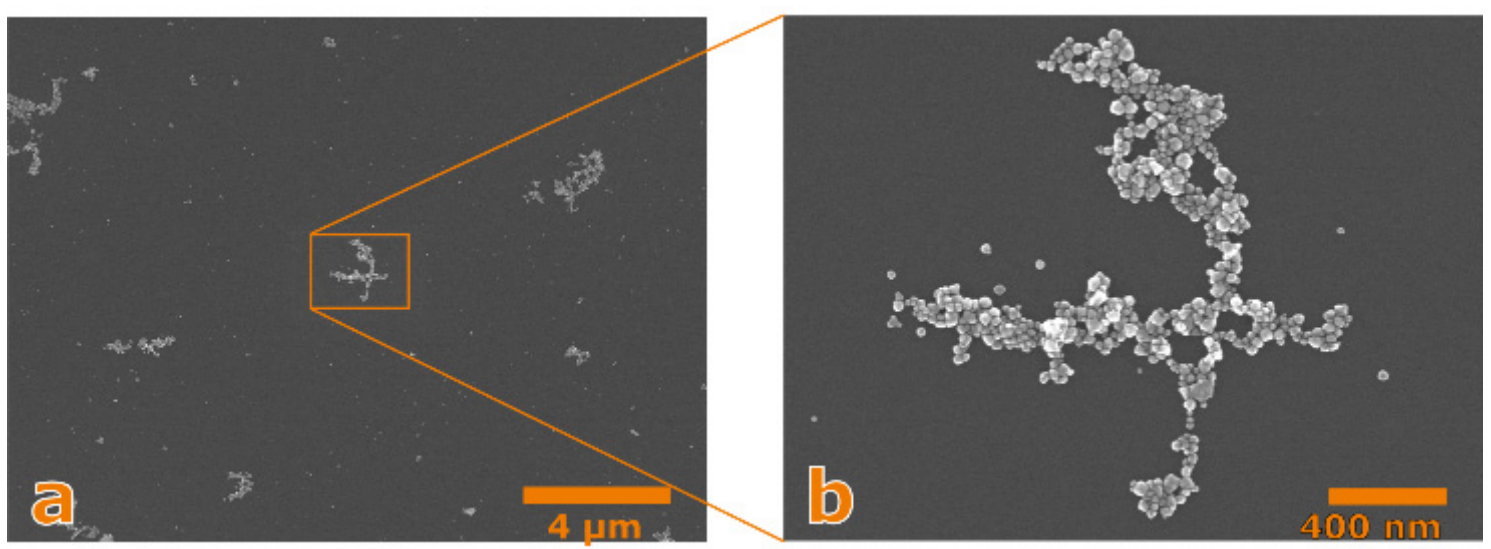

Figure 4. Formation of larger filamentous gold nanoparticle aggregates by the reduction of $\mathrm{HAuCl}_{4}(50 \mu \mathrm{M})$ with ascorbic acid $(100 \mu \mathrm{M})$ in the presence of poly-DADMAC (5 ppm): (a) SEM image showing several aggregates, (b) SEM imaging showing one filamentous aggregate at enhanced magnification.

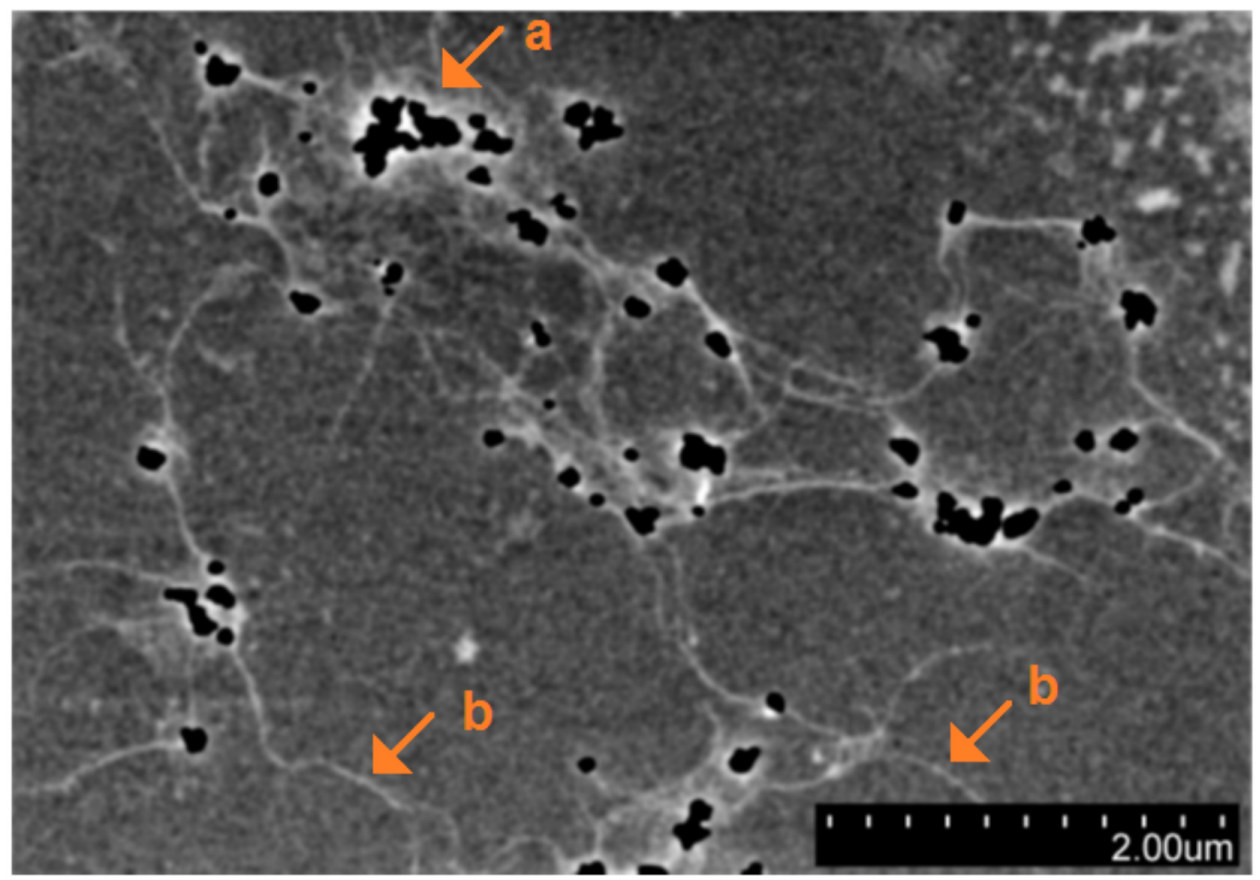

Figure 5. SEM images (overlay of contrast-enhanced images) of the aggregation of gold nanoparticles formed by the reduction of $\mathrm{HAuCl}_{4}(20 \mu \mathrm{M})$ with ascorbic acid $(60 \mu \mathrm{M})$ in the presence of poly-DADMAC (100 ppm): (a) larger cluster of metal nanoparticles; (b) macromolecular filaments. 
The present nanoparticle structures suggest the formation of a hierarchical organization of gold nanoparticles in the aggregates. Therefore, four levels of structural complexity could be identified (Figure 6): The single compact gold nanoparticles represent the first level. These gold nanoparticles can be small compact nanocrystals or even nearly spherical polynuclear gold nanoparticles which are formed by a nucleation/assembling mechanism, as discovered by Polte et al. [46]. The typical size of these particles is in the order of magnitude of $10 \mathrm{~nm}$. The second level is marked by aggregates of these particles found in the form of compact particle clusters (see, e.g., Figure 1f) with typical diameters in the range between about 20 and $100 \mathrm{~nm}$. The third level of particle assembling supplies aggregates with diameters in the submicron range. It can be found either in the form of composed dendritic particles with a granular surface (Figure 1b) or in the form of aggregates of smaller particle clusters as shown in Figure 1h. These particles have the character of superclusters because they consist of smaller particles and particle clusters. Finally, the fourth level of assembling is related to aggregates of the superclusters. Their size is typically above one micron. High-contrast SEM images support the assumption that these filamentous particles are formed by networks integrating macromolecular filaments and filament-bonded metal nanoparticles.
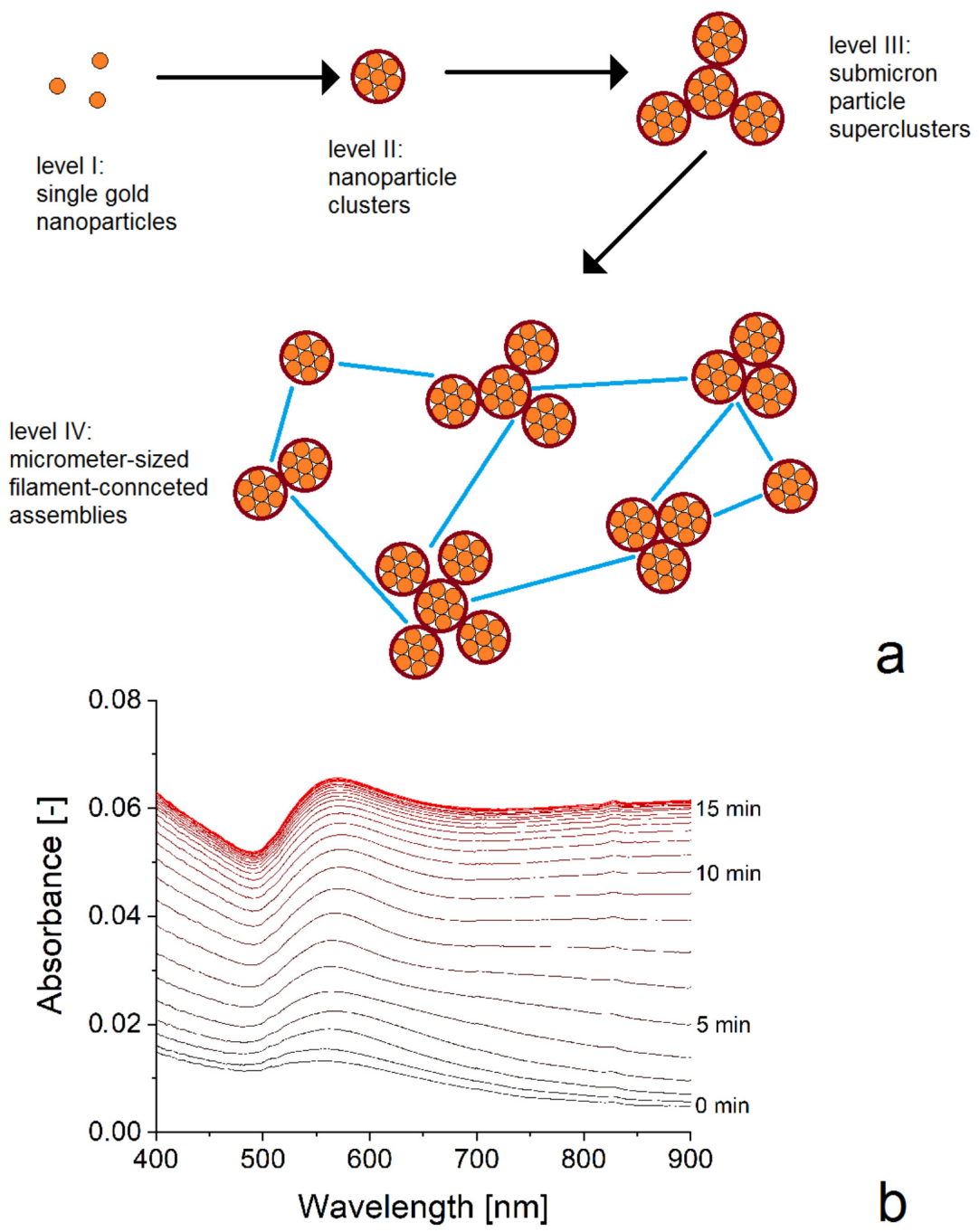

a

Figure 6. Evolution of particle formation and assembly: (a) illustration of structural hierarchy in the formation and assembly of gold nanoparticles during their formation by the reduction of $\mathrm{HAuCl}_{4}$ with ascorbic acid; (b) example of temporal evolution reflecting the formation of single particles in the beginning (first measurement cycles) and later increasing long-wavelength absorption indicating the formation of particle clusters. 
The effect of poly-DADMAC is not limited to causing particle attachment. In addition, the application of these polycationic molecules influences the particle nucleation and growth. The addition of a final concentration of $100 \mathrm{ppm}$ poly-DADMAC leads to a significant reduction in the formation rate of small spherical or compact nanoparticles with the characteristic resonance at about $550 \mathrm{~nm}$ (Figure 7a) and to a significant enhancement of absorption in the NIR range (Figure $7 \mathrm{~b}$ ). In experiments with a reduced concentration of ascorbic acid of $60 \mu \mathrm{M}$ and $70 \mu \mathrm{M} \mathrm{HAuCl4}$, this long-wavelength absorption is related to the formation of nonspherical gold nanoparticles with higher aspect ratios (Figure 8a-d). In addition, it is remarkable that the increase of $550 \mathrm{~nm}$ absorption in the presence of poly-DADMAC occurs approximately linearly, which indicates a slow and nearly constant formation rate of small gold nanoparticles (1-min intervals in Figure 7c). In contrast, the absorption at $800 \mathrm{~nm}$ shows an increasing growth rate for the first measurement cycles (Figure 7c). This indicates an accelerated process. This can be interpreted as a comparatively low rate of nucleation for gold nanocrystals that are able to grow and as an acceleration of gold deposition on growing nanocrystals due to the increase in crystal surface area. Indeed, the formation of some flat, regular nanoprisms with side lengths above one micrometer has been observed in the related sample (Figure 8a). A further enhancement of polyDADMAC concentration promotes the formation of fractal gold nanocrystals (Figure 8b-d). Highly fractal nanoparticles with a high specific surface area (Figure 1h) are formed by a combination of dendritic crystal growth and attachment of small gold nanoparticles on the crystal surface. The formation of highly structured particles with a typical size in the submicron range can be also generated by the common addition of small amounts of a polyanionic macromolecule PSS to the poly-DADMAC-containing solution (Figure 8e).

It is assumed that the effect of the poly-DADMAC is mainly related to the electrostatic effect of macromolecules adsorbing onto the surface of growing nanoparticles. An excess of positive charge on particles during the growth process can lower the growth rates, on the one side. On the other side, it causes a self-polarization effect in the case of nonspherical particles. This could be the reason for the preferential edge- and corner-oriented growth of flat gold nanoprisms induced by an attractive Coulomb interaction between the positively polarized particle corners and the negatively charged tetrachloroaurate. The formation of nonspherical, star-like and special-shaped crystalline gold nanoparticles [31-33] depends on the empirically optimized composition of reaction solutions and is known to be related to symmetry breaking during nanoparticle formation [47].

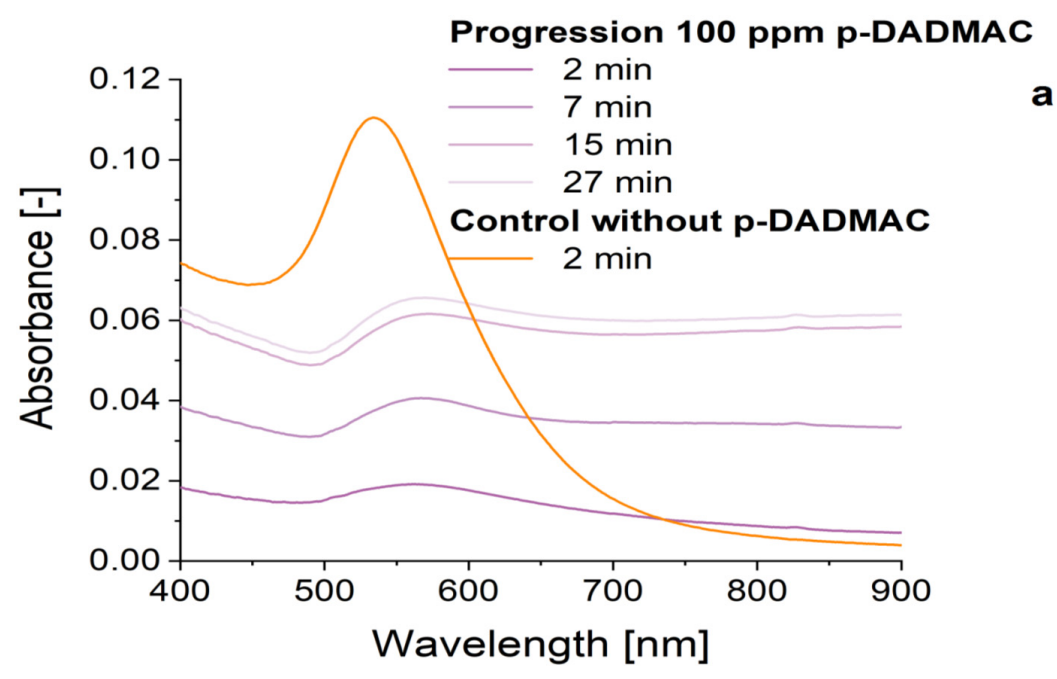

Figure 7. Cont. 

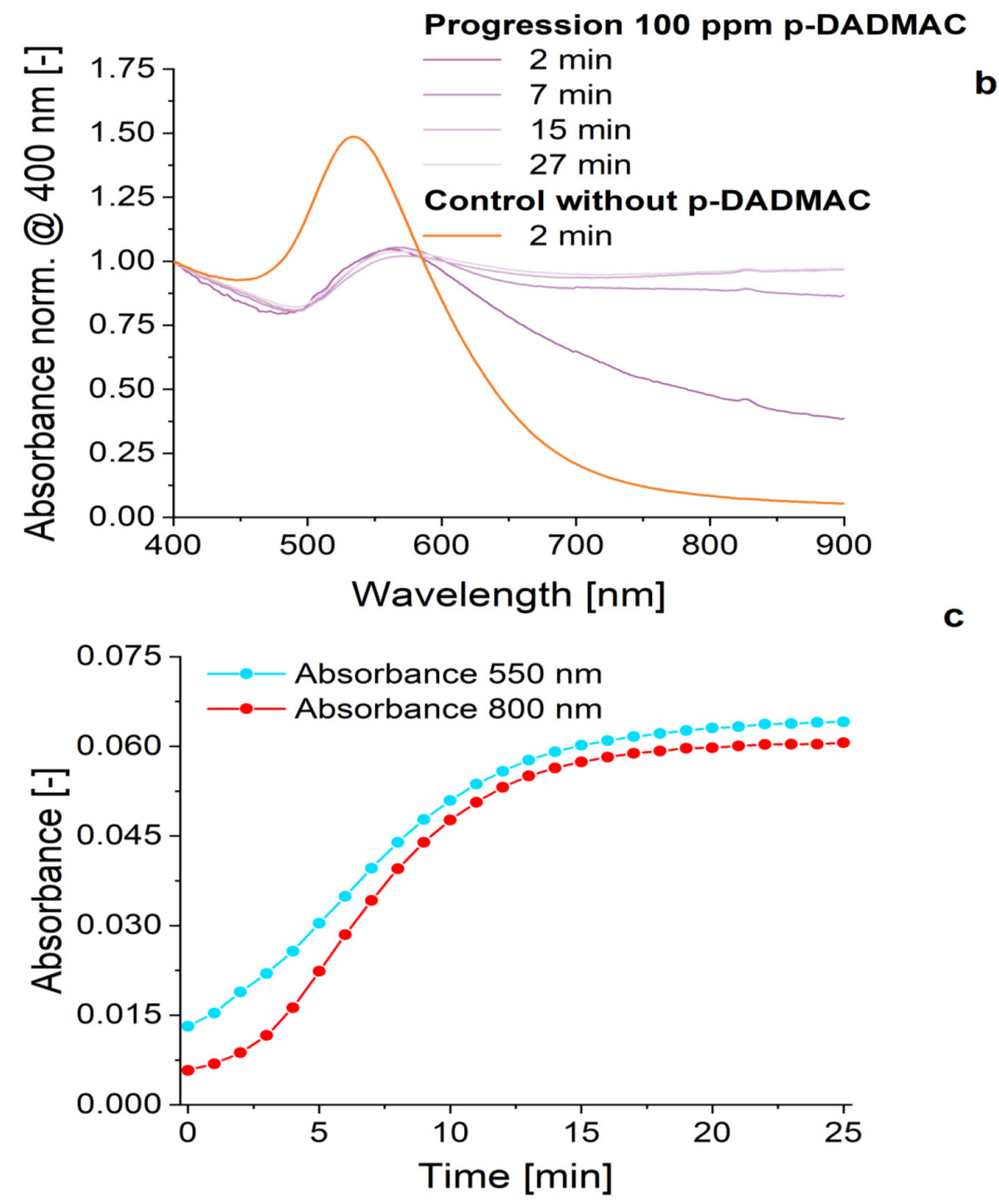

Figure 7. Effect of poly-DADMAC on the evolution of the characteristic electromagnetic resonance of forming gold nanoparticles (70 $\mu \mathrm{M} \mathrm{HAuCl}_{4}, 60 \mu \mathrm{M}$ ascorbic acid). (a) Evolution of the spectra over time, (b) evolution of the normalized spectra over time (normalized to $400 \mathrm{~nm}$ ) and (c) fast initial growth of the absorbance at $550 \mathrm{~nm}$ and increasing growth rate of NIR absorbance.
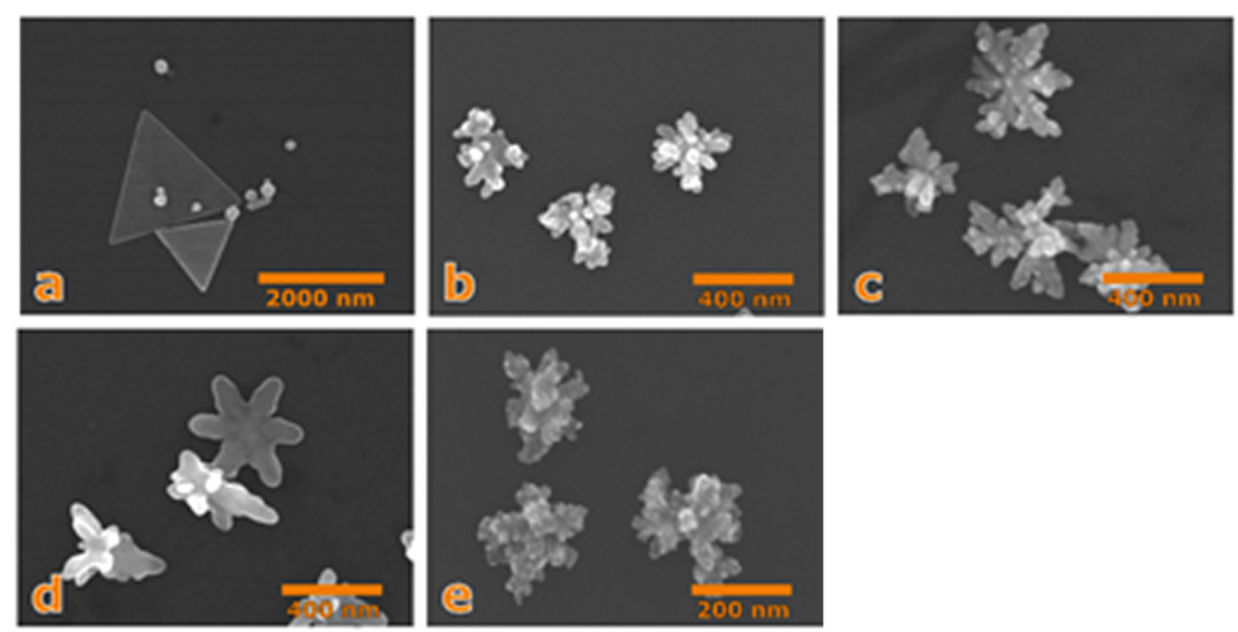

Figure 8. Typical nonspherical gold nanoparticles forming in the presence of poly-DADMAC: $(\mathbf{a}, \mathbf{b})$ $70 \mu \mathrm{M} \mathrm{HAuCl}_{4}, 60 \mu \mathrm{M}$ ascorbic acid, $100 \mathrm{ppm}$ poly-DADMAC; (c) $70 \mu \mathrm{M} \mathrm{HAuCl}_{4}, 60 \mu \mathrm{M}$ ascorbic acid, 250 ppm poly-DADMAC; (d) $70 \mu \mathrm{M} \mathrm{HAuCl}_{4}, 60 \mu \mathrm{M}$ ascorbic acid, 400 ppm poly-DADMAC; (e) $50 \mu \mathrm{M} \mathrm{HAuCl}_{4}, 100 \mu \mathrm{M}$ ascorbic acid, 60 ppm poly-DADMAC, 10 ppm PSS. 


\section{Conclusions}

The investigations confirm the fact that the addition of the polycationic water-soluble polymer poly-DADMAC causes significant changes in the growth and aggregation behavior of gold nanoparticles. The charged polymer is responsible for the modulation of nucleation and growth rate of gold nanoparticles, as well as for their interaction and incorporation in larger clusters and assemblies. As a result, different types of nanoparticle aggregates with sizes between about $20 \mathrm{~nm}$ and several microns are formed. SEM images suggest at least three different aggregation levels of nanoparticles can be distinguished, which can be described as hierarchically organized aggregate structures.

The shapes and sizes of nanoparticle structures can be controlled by the concentration ratios of the metal precursor, the reducing agent and the macromolecular additives. Thus, nanoparticle assemblies with a dendritic structure and high specific surface area can be generated. These particles are of interest for catalytic and analytical applications such as plasmonic sensing and surface-enhanced Raman scattering (SERS). The cyclic photospectrometric measurements do not reflect a sedimentation of aggregates after $15 \mathrm{~min}$. Particles sedimented after several hours can be redispersed by support of ultrasound.

Supplementary Materials: The following are available online at https:/ / www.mdpi.com/2076-341 7/11/3/1191/s1, Figure S1: cyclic photometry data, Table S1: DLS data.

Author Contributions: Synthesis experiments (J.M.K., J.K.), particle characterization (J.M.K., J.K.), writing manuscript (J.M.K., J.K.), final manuscript editing (J.K.). All authors have read and agreed to the published version of the manuscript.

Funding: The financial support of Deutsche Forschungsgemeinschaft (Kz KO 1403/45-1) is gratefully acknowledged.

Institutional Review Board Statement: In the investigations, no studies on humans and no experiments with animals have been performed.

Informed Consent Statement: In the investigations, no studies on humans and no experiments with animals have been performed.

Data Availability Statement: There are no publicly archivated supporting data sets.

Conflicts of Interest: The authors declare no conflict of interest.

\section{References}

1. Homberger, M.; Simon, U. On the application potential of gold nanoparticles in nanoelectronics and biomedicine. Philos. Trans. R. Soc. A-Math. Phys. Eng. Sci. 2010, 368, 1405-1453. [CrossRef] [PubMed]

2. Link, S.; El-Sayed, M.A. Spectral properties and relaxation dynamics of surface plasmon electronic oscillations in gold and silver nanodots and nanorods. J. Phys. Chem. B 1999, 103, 8410-8426. [CrossRef]

3. Reichert, J.; Csaki, A.; Kohler, J.M.; Fritzsche, W. Chip-based optical detection of DNA hybridization by means of nanobead labeling. Anal. Chem. 2000, 72, 6025-6029. [CrossRef] [PubMed]

4. Csaki, A.; Kaplanek, P.; Moller, R.; Fritzsche, W. The optical detection of individual DNA-conjugated gold nanoparticle labels after metal enhancement. Nanotechnology 2003, 14, 1262-1268. [CrossRef] [PubMed]

5. Bunz, U.H.F.; Rotello, V.M. Gold Nanoparticle-Fluorophore Complexes: Sensitive and Discerning "Noses" for Biosystems Sensing. Angew. Chem. Int. Edit. 2010, 49, 3268-3279. [CrossRef] [PubMed]

6. Hwang, W.S.; Truong, P.L.; Sim, S.J. Size-dependent plasmonic responses of single gold nanoparticles for analysis of biorecognition. Anal. Biochem. 2012, 421, 213-218. [CrossRef]

7. Jia, H.; Fang, C.; Zhu, X.-M.; Ruan, Q.; Wang, Y.-X.J.; Wang, J. Synthesis of Absorption-Dominant Small Gold Nanorods and Their Plasmonic Properties. Langmuir 2015, 31, 7418-7426. [CrossRef]

8. Murphy, C.J.; San, T.K.; Gole, A.M.; Orendorff, C.J.; Gao, J.X.; Gou, L.; Hunyadi, S.E.; Li, T. Anisotropic metal nanoparticles: Synthesis, assembly, and optical applications. J. Phys. Chem. B 2005, 109, 13857-13870. [CrossRef]

9. González, A.L.; Noguez, C. Influence of Morphology on the Optical Properties of Metal Nanoparticles. J. Comput. Theor. Nanosci. 2007, 4, 231-238. [CrossRef]

10. Penn, S.G.; He, L.; Natan, M.J. Nanoparticles for bioanalysis. Curr. Opin. Chem. Biol. 2003, 7, 609-615. [CrossRef]

11. Haes, A.J.; Zou, S.L.; Schatz, G.C.; van Duyne, R.P. Nanoscale optical biosensor: Short range distance dependence of the localized surface plasmon resonance of noble metal nanoparticles. J. Phys. Chem. B 2004, 108, 6961-6968. [CrossRef] 
12. Gumbi, B.; Ngila, J.C.; Ndungu, P.G. Gold nanoparticles for the quantification of very Low levels of poly-diallyldimethylammonium chloride in river water. Anal. Methods 2014, 6, 6963-6972. [CrossRef]

13. Magubane, S.E.; Ntlhoro, S.; Sabela, M.; Kanchi, S.; Mlambo, M.; Onwubu, S.C.; Mdluli, P.S.; Inamuddin; Asiri, A.M. Novel on-site residual screening of poly-diallyldimethylammonium chloride in treated potable water using gold nanoparticle based lovibond color filters. J. Taiwan Inst. Chem. Eng. 2019, 101, 159-166. [CrossRef]

14. Capek, I. Noble Metal Nanoparticles: Preparation, Composite Nanostructures, Biodecoration and Collective Properties; Springer: Berlin, Germany, 2017; pp. 211-316.

15. Pelras, T.; Mahon, C.S.; Nonappa, O.I.; Gröschel, A.H.; Müllner, M. Polymer nanowires with highly precise internal morphology and topography. JACS 2018, 140, 12736-12740. [CrossRef] [PubMed]

16. Moulin, E.; Armao IV, J.J.; Guiseppone, N. Triarylamine-based supramolecular polymers: Structures, dynamics, and functions. Acc. Chem. Res. 2019, 52, 975-983. [CrossRef] [PubMed]

17. Wang, Z.; Wang, H.; Cheng, M.; Li, C.; Faller, R.; Sun, S.; Hu, S. Controllable multigeometry nanoparticles via cooperative assembly by amphiphilic diblock copolymer blends with asymmetric architectures. ACS Nano 2018, 12, 1413-1419. [CrossRef]

18. Smith, J.D.; Scanlan, M.M.; Chen, A.N.; Ashberry, H.M.; Skrabalak, S.E. Kinetically controlled sequential seeded growth: A general route to crystals with different hierarchies. ACS Nano 2020, 14, 15953-15961. [CrossRef] [PubMed]

19. Lunn, D.J.; Finnegan, J.R.; Manners, I. Self-assembly of patchy nanoparticles: A versatile approach to functional hierarchical materials. Chem. Sci. 2015, 6, 3663-3673. [CrossRef]

20. Maji, A.; Beg, M.; Das, S.; Sahoo, N.K.; Jha, P.K.; Islam, M.M.; Hossain, M. Binding interaction study on human serum albumin with bactericidal gold nanoparticles synthesized from a leaf extract of Musa balbisiana: Amultispectroscopic approach. Luminescence 2019, 34, 6. [CrossRef]

21. Lengert, E.; Saveleva, M.; Abalymov, A.; Atkin, V.; Wuytens, P.C.; Kamyshinsky, R.; Vasiliev, A.L.; Gorin, D.A.; Sukhorukov, G.; Skirtach, A.; et al. Silver alginate hydrogel micro and nanocontainers for thernostics: Synthesis, encapsulation, remote release, and detection. ACS Appl. Mat. Interfaces 2017, 9, 21949-21958. [CrossRef]

22. Brasili, F.; Capocefalo, A.; Palmieri, D.; Capitani, F.; Chiessi, E.; Paradossi, G.; Bordi, F.; Domenici, F. Assembling patchy plasmonic nanoparticles with aggregation-dependent antibacterial activity. J. Colloid Interface Sci. 2020, 580, 419-428. [CrossRef] [PubMed]

23. Cozzoli, P.D.; Manna, L. Synthetic Strategies to Size and Shape Controlled Nanocrystals and Nanocrystal Heterostructures. In Bio-Applications of Nanoparticles; Chan, W.C.W., Ed.; Springer: New York, NY, USA, 2007; pp. 1-17.

24. Meyer, M.; Le Ru, E.C.; Etchegoin, P.G. Self-limiting aggregation leads to long-lived metastable clusters in colloidal solutions. J. Phys. Chem. B 2006, 110, 6040-6047. [CrossRef] [PubMed]

25. Sanchez, C.; Soler-Illia, G.; Ribot, F.; Lalot, T.; Mayer, C.R.; Cabuil, V. Designed hybrid organic-inorganic nanocomposites from functional nanobuilding blocks. Chem. Mat. 2001, 13, 3061-3083. [CrossRef]

26. Cozzoli, P.D.; Pellegrino, T.; Manna, L. Synthesis, properties and perspectives of hybrid nanocrystal structures. Chem. Soc. Rev. 2006, 35, 1195-1208. [CrossRef]

27. Zeng, C. Precision at the nanoscale: On the structure and property evolution of gold nanoclusters. Pure Appl. Chem. 2018, 90, 1409-1427. [CrossRef]

28. Lofton, C.; Sigmund, W. Mechanisms controlling crystal habits of gold and silver colloids. Adv. Funct. Mater. 2005, 15, 1197-1208. [CrossRef]

29. Koehler, J.M.; Visaveliya, N.; Knauer, A. Controlling formation and assembling of nanoparticles by control of electrical charging, polarization, and electrochemical potential. Nanotechnol. Rev. 2014, 3, 553-568. [CrossRef]

30. Koehler, J.M.; Romanus, H.; Huebner, U.; Wagner, J. Formation of star-like and core-shell AuAg nanoparticles during two- and three-step preparation in batch and in microfluidic systems. J. Nanomater. 2007. [CrossRef]

31. Koehler, J.M.; Kluitmann, J.; Knauer, A. Metal Nano Networks by Potential-Controlled In Situ Assembling of Gold/Silver Nanoparticles. ChemistryOpen 2019, 8, 1369-1374. [CrossRef]

32. Visaveliya, N.; Knauer, A.; Yu, W.; Serra, C.A.; Koehler, J.M. Microflow-assisted assembling of multi-scale polymer particles by controlling surface properties and interactions. Eur. Polym. J. 2016, 80, 256-267. [CrossRef]

33. Kohler, J.M.; Wagner, J.; Albert, J.; Mayer, G.; Hubner, U. Formation of gold nano-particles and nano-particle aggregates in static micromixers in the presence of bovine serum albumin (BSA). Chem. Ing. Tech. 2005, 77, 867-873.

34. Visaveliya, N.; Knauer, A.; Köhler, J.M. Application of polyionic macromolecules in micro flow syntheses of nanoparticles. Macromol. Chem. Phys. 2017, 218, 1600371. [CrossRef]

35. Wang, X.; Yang, D.-P.; Huang, P.; Li, M.; Li, C.; Chen, D.; Cui, D. Hierarchically assembled Au microspheres and sea urchin-like architectures: Formation mechanism and SERS study. Nanoscale 2012, 4, 7766-7772. [CrossRef] [PubMed]

36. Höller, R.P.; Dulle, M.; Thomä, S.; Mayer, M.; Steiner, A.M.; Förster, S.; Fery, A.; Kuttner, C.; Chanana, M. Protein-assisted assembly of modular 3D plasmonic raspberry-like core/satellite nanoclusters: Correlation of structure and optical properties. ACS Nano 2016, 10, 5740-5750. [CrossRef] [PubMed]

37. Köhler, J.M.; Wagner, J.; Albert, J. Formation of isolated and clustered Au nanoparticles in the presence of polyelectrolyte molecules using a flow-through Si chip reactor. J. Mater. Chem. 2005, 15, 1924-1930. [CrossRef]

38. Köhler, J.M.; Wagner, J.; Albert, J.; Mayer, G.; Hübner, U. Bildung von Goldnanopartikeln und Nanopartikelaggregaten in statischen Mikromischern in Gegenwart von Rinderserumalbumin. Chem. Ing. Tech. 2005, 77, 867-873. [CrossRef] 
39. Aherne, D.; Ledwith, D.M.; Gara, M.; Kelly, J.M. Optical Properties and Growth Aspects of Silver Nanoprisms Produced by a Highly Reproducible and Rapid Synthesis at Room Temperature. Adv. Funct. Mater. 2008, 18, 2005-2016. [CrossRef]

40. Knauer, A.; Visaveliya, N.; Koehler, J.M. Spontaneous transformation of polyelectrolyte-stabilized silver nanoprisms by interaction with thiocyanate. J. Colloid Interface Sci. 2013, 394, 78-84. [CrossRef]

41. Jana, N.R.; Gearheart, L.; Murphy, C.J. Evidence for Seed-Mediated Nucleation in the Chemical Reduction of Gold Salts to Gold Nanoparticles. Chem. Mat. 2001, 13, 2313-2322. [CrossRef]

42. Wagner, J.; Köhler, J.M. Continuous Synthesis of Gold Nanoparticles in a Microreactor. Nano Lett. 2005, 5, 685-691. [CrossRef]

43. Senthil Kumar, P.; Pastoriza-Santos, I.; Rodriguez-Gonzalez, B.; de Abajo, G.; Javier, F.; Liz-Marzan, L.M. High-yield synthesis and optical response of gold nanostars. Nanotechnology 2008, 19, 015606. [CrossRef] [PubMed]

44. Khoury, C.G.; Vo-Dinh, T. Gold Nanostars for Surface-Enhanced Raman Scattering: Synthesis, Characterization and Optimization. J. Phys. Chem. C 2008, 112, 18849-18859. [CrossRef] [PubMed]

45. Xiao, J.; Qi, L. Surfactant-assisted, shape-controlled synthesis of gold nanocrystals. Nanoscale 2011, 3, 1383-1396. [CrossRef] [PubMed]

46. Polte, J.; Ahner, T.T.; Delissen, F.; Sokolov, S.; Emmerling, F.; Thuenemann, A.F.; Kraehnert, R. Mechanism of Gold Nanoparticle Formation in the Classical Citrate Synthesis Method Derived from Coupled In Situ XANES and SAXS Evaluation. J. Am. Chem. Soc. 2010, 132, 1296-1301. [CrossRef]

47. Viswanath, B.; Kundu, P.; HaIder, A.; Ravishankar, N. Mechanistic Aspects of Shape Selection and Symmetry Breaking during Nanostructure Growth by Wet Chemical Methods. J. Phys. Chem. C 2009, 113, 16866-16883. [CrossRef] 